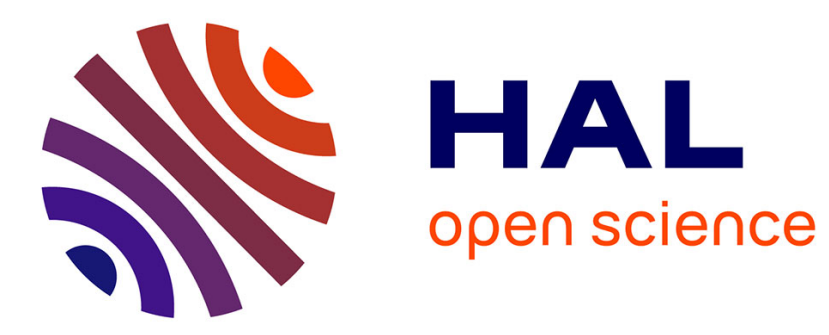

\title{
Protection of civilian population
}

\author{
A. Guinet, Tao Wang
}

\section{To cite this version:}

A. Guinet, Tao Wang. Protection of civilian population. 21ème Journées internationales de l'INSA (2018), Oct 2018, Villeurbanne, France. hal-01900528

\section{HAL Id: hal-01900528 \\ https://hal.science/hal-01900528}

Submitted on 22 Oct 2018

HAL is a multi-disciplinary open access archive for the deposit and dissemination of scientific research documents, whether they are published or not. The documents may come from teaching and research institutions in France or abroad, or from public or private research centers.
L'archive ouverte pluridisciplinaire HAL, est destinée au dépôt et à la diffusion de documents scientifiques de niveau recherche, publiés ou non, émanant des établissements d'enseignement et de recherche français ou étrangers, des laboratoires publics ou privés. 


\section{PROTECTION OF CIVILIAN POPULATION}

\section{A. Guinet}

a.guinet@insa-lyon.fr

Diagnosis and assistance to territorial governance
Pr. A. Guinet,

Dr. T. Wang

CIPS 5056 : Threats

ARC2 : PrHodom
CENTRE HOSPITALIER

Gaint Joseph • Saint Luc aU CEEUR DE LA VILLE

\section{SOINS ET SANTÉ}

Hospitalisation A Domicile

\section{Industrial problem:}

- Access to victims, access to care, access to information.

- Develop emergency management processes supported by decision making tools. Scientific problem:

- Propose a vulnerability analysis approach.

- Model, evaluate, size and support the emergency management processes of the health network to deal with a sanitary crisis.

Key-words: Sanitary crises, Vulnerability, Emergency management processes, Mitigation, Response.

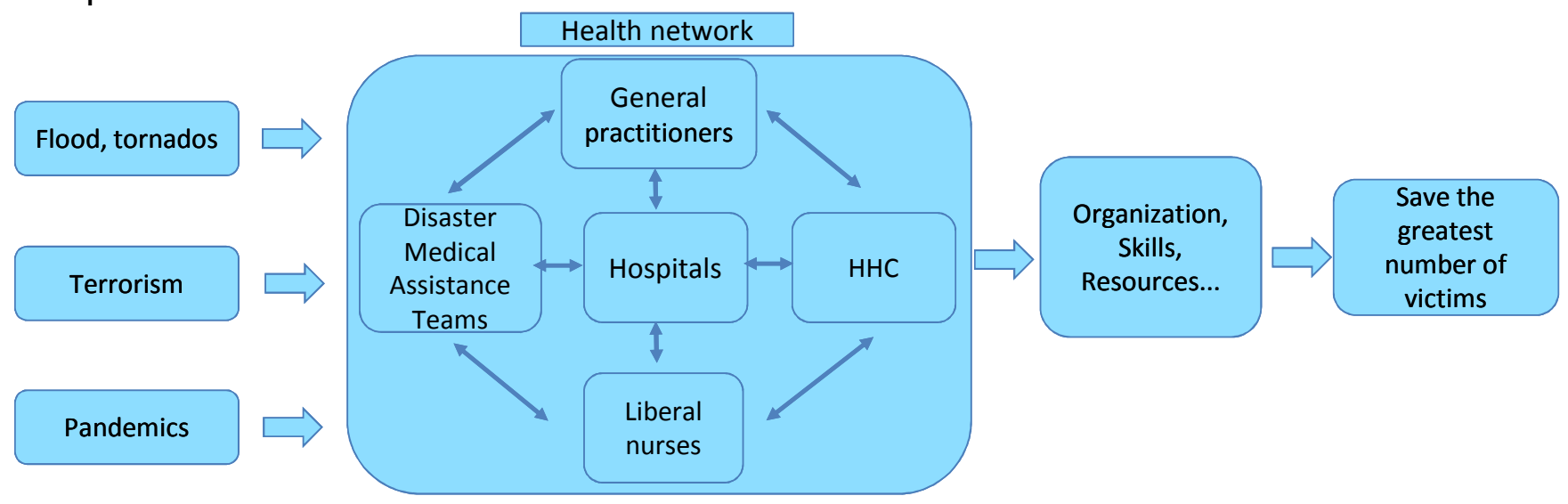

\begin{tabular}{|c|c|c|c|c|c|c|}
\hline $\begin{array}{l}\text { Natural or human } \\
\text { crisis }\end{array}$ & $\longrightarrow$ & $\begin{array}{c}\text { Vulnerability analysis approach, Critical } \\
\text { processes, Impact assessment... }\end{array}$ & $\square$ & $\begin{array}{c}\text { Emergency } \\
\text { management } \\
\text { processes }\end{array}$ & $\Longrightarrow$ & $\begin{array}{l}\text { Mitigation and } \\
\text { response } \\
\text { models }\end{array}$ \\
\hline
\end{tabular}

- $\quad$ Chen W., A. Guinet, A. Ruiz, (2016). Modeling the Logistics Response to a Bioterrorist Anthrax Attack. European Journal of Operational Research, 254, 458-471.

- Guinet. A. (2017). How to protect a hospital against cyber attacks. Springer. Third International Conference on Health Care Systems Engineering, May, Florence (Italy). Springer Proceedings in Mathematics \& Statistics, 1-13.

- Guinet, A., Barkaoui, H., Wang, T., Dubost E. (2017). A mitigation tool to protect a home health care structure facing a hydrological disaster. IFAC 2017 World Congress, Toulouse (France). IFAC-PapersOnLine, 50(1), 4630-4635

- Guinet A., Barkaoui H., Wang T., Dubost E. (2018). An Emergency Management Plan to Face a Foodborne Criminal Attack. Seventh International Conference on Information Systems, Logistics and Supply Chain, July, Lyon (France), Hal proceedings, 1-10. 